\title{
Management of coronary artery arising from nonfacing sinus in transposition of great arteries
}

\author{
T. K. Susheel Kumar, MD, ${ }^{a}$ Nomisha Amin, MD, ${ }^{\mathrm{b}}$ Shyam Sathanandam, MD, ${ }^{\mathrm{b}}$ and \\ Christopher J. Knott-Craig, MD, ${ }^{a}$ Memphis, Tenn
}

\footnotetext{
From the Departments of a Pediatric Cardiothoracic Surgery and 'Pediatric Cardiology, Le Bonheur Children's Hospital and University of Tennessee Health Science Center, Memphis, Tenn.

Disclosures: Authors have nothing to disclose with regard to commercial support.

Received for publication Jan 22, 2018; revisions received April 13, 2018; accepted for publication April 24, 2018; available ahead of print June 20, 2018

Address for reprints: T. K. Susheel Kumar, MD, Department of Pediatric Cardiothoracic Surgery, Le Bonheur Children's Hospital, University of Tennessee Health Science Center, Memphis, TN 38103 (E-mail: tskumar@uthsc.edu).

J Thorac Cardiovasc Surg 2018;156:e189-90

$0022-5223 / \$ 36.00$

Copyright (C) 2018 by The American Association for Thoracic Surgery

https://doi.org/10.1016/j.jtcvs.2018.04.116
}

The success of the arterial switch operation (ASO) performed for transposition of the great vessels or TaussigBing anomaly (TBA) largely depends on the safe translocation of the coronary arteries into the neoaorta. ${ }^{1}$ However, variations in coronary pattern can pose surgical challenges and are associated with higher mortality and morbidity. 1,2 A number of coronary variations have been described and categorized in the literature. ${ }^{1,3}$ We describe the management of a patient with TBA with the major coronary artery arising from the nonfacing sinus, a variation hitherto not described in literature.

\section{CASE DESCRIPTION}

A newborn infant born at full term was diagnosed with Goldenhar syndrome and cardiac defect consisting of double-outlet right ventricle with transposition physiology. The great vessels were located side by side with a large subpulmonic ventricular septal defect (VSD). The coronary arteries appeared to be unusual with the right coronary artery (RCA) and left anterior descending (LAD) coming far off the right nonfacing sinus and the circumflex (CX) artery emerging as a single branch from the posterior facing sinus (Figure 1, A). Cardiac catheterization confirmed the abnormal coronary anatomy with the RCA and LAD arising from the nonfacing sinus and the $\mathrm{CX}$ arising from the posterior facing sinus. At operation, the RCA was seen arising from the middle of the nonfacing sinus well below the level of the commissures, and this immediately gave rise to the LAD. The CX artery arose from the posterior facing sinus. No coronary artery was seen arising from the anterior facing sinus. The coronary anatomy was deemed unsuitable for a traditional ASO. The Damus-Kaye-Stansel operation with the Rastelli procedure was performed. The LAD coursed anteriorly just below the pulmonary annulus. The incision on the right ventricle for VSD baffle and proximal anastomosis of the conduit was placed well below the level

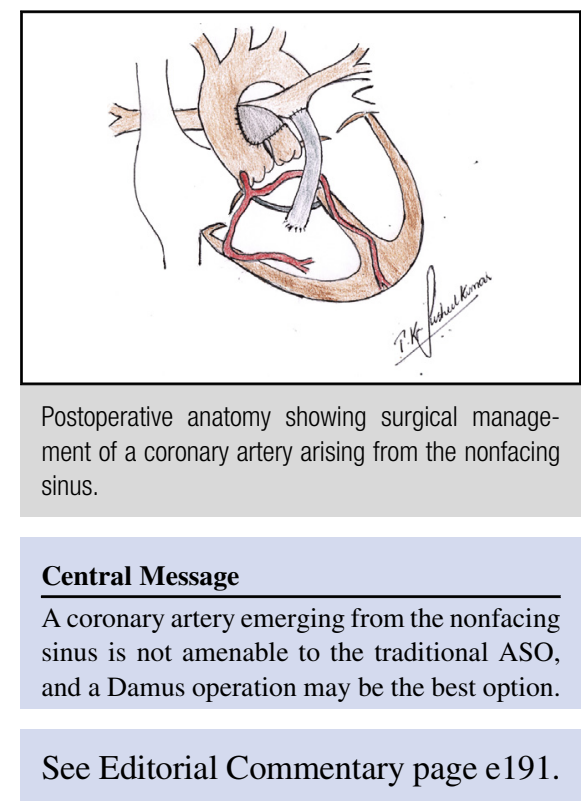

of the LAD. A right ventricle to pulmonary artery conduit in the form of a 12-mm femoral vein was placed (Figure 1, B). The patient had an uneventful postoperative course and has continued to do well on follow-up of more than 1 year.

\section{Comment}

Coronary anomalies are well described in transposition of the great vessels and are more common in TBA. ${ }^{4}$ Various systems of classification have been proposed. ${ }^{1,3,4}$ However, a coronary artery arising from the nonfacing sinus is not described in the literature. In our patient, the RCA arose from the middle of the nonfacing sinus and immediately gave rise to the LAD. It then entered the right atrioventricular groove. The LAD crossed the right ventricular outflow tract close to the pulmonary annulus before entering the anterior interventricular groove. Surgical management of such a coronary artery can be a challenge. Traditional ASO with coronary reimplantation was not a feasible option in our patient. Coronary lengthening procedures were not considered an option because the distance between the coronary orifice and the neoaorta was considerable (nearly equal to the diameter of the aorta) and the coronary orifice was well below the top of commissural post. ${ }^{5}$ The atrial switch, the Damus procedure with closure of VSD, and techniques involving creation of aortopulmonary window and pericardial baffle 

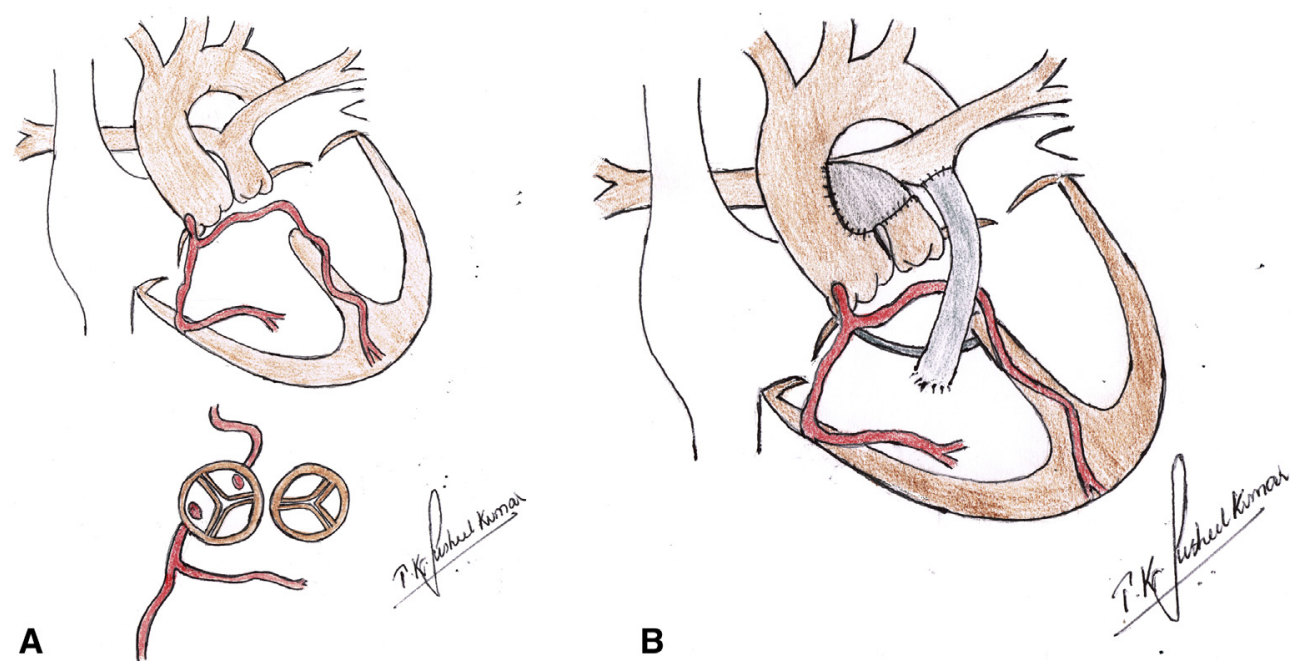

FIGURE 1. A, Preoperative anatomy is demonstrated with side-by-side great vessels and a single coronary ostium in the nonfacing sinus (the most rightward sinus) of the aorta. The RCA emerges from the nonfacing sinus and immediately gives rise to the left coronary artery (LAD), which courses in front of the right ventricular outflow tract. The CX artery emerges from the posterior facing sinus. B, Postoperative anatomy showing surgical management of coronary arising from nonfacing sinus.

without actual coronary translocations are options one should consider when ASO is not feasible. The atrial switch commits the right ventricle to the systemic circulation and does not have good long-term results. Techniques involving creation of an aortopulmonary window and pericardial baffle are not feasible options when the coronary artery arises from the nonfacing sinus. ${ }^{6-8}$ The Damus operation, which involves a proximal aortopulmonary anastomosis, was a good option in our patient. ${ }^{9}$ Although we baffled the VSD to the aorta, one may just close the VSD. The higher pressure in the left side prevents the opening of the native aortic valve. Thus, this technique is also an option in patients with challenging coronary anatomy and an intact ventricular septum.

\section{References}

1. Pasquali SK, Hasselblad V, Li JS, Kong DF, Sanders SP. Coronary artery pattern and outcome of arterial switch operation for transposition of the great arteries: a meta-analysis. Circulation. 2002;106:2575-80.
2. Villafane J, Lantin-Hermoso MR, Bhatt AB, Tweddell JS, Geva T, Nathan M, et al. D-transposition of the great arteries: the current era of the arterial switch operation. J Am Coll Cardiol. 2014;64:498-511.

3. Wernovsky G, Sanders SP. Coronary artery anatomy and transposition of the great arteries. Coron Artery Dis. 1993:4:148-57.

4. Wang C, Chen S, Zhang H, Liu J, Xu Z, Zheng J, et al. Anatomical classifications of the coronary arteries in complete transposition of the great arteries and double outlet right ventricle with subpulmonary ventricular septal defect. J Thorac Cardiovasc Surg. 2017;65:26-30.

5. Talwar S, Shivaprasad MB, Kothari SS, Choudhary SK. A novel conduitlengthening technique to facilitate the arterial switch operation in an infant with a problematic combination of coronary anomalies. Tex Heart Inst J. 2009;36: 234-7.

6. Aubert J, Pannetier A, Couvelly JP, Unal D, Rouault F, Delarue A. Transposition of the great arteries. New technique for anatomical correction. Br Heart J. 1978;40: 204-8.

7. Takeuchi S, Katogi T. New technique for the arterial switch operation in difficult situations. Ann Thorac Surg. 1990;50:1001.

8. Moat NE, Pawade A, Lamb RK. Complex coronary arterial anatomy in transposition of the great arteries. Arterial switch procedure without coronary relocation. $J$ Thorac Cardiovasc Surg. 1992;103:872-6.

9. Damus PS, Thomson NB Jr, McLoughlin TG. Arterial repair without coronary relocation for complete transposition of the great vessels with ventricular septal defect. Report of a case. J Thorac Cardiovasc Surg. 1982;83:316-8. 